\title{
EVALUATION OF MESHED REFERENCE PLANES FOR HIGH PERFORMANCE APPLICATIONS
}

\author{
N. D. CODREANU ${ }^{\mathrm{a}, *}$, P. SVASTA ${ }^{\mathrm{a}}$, \\ V. GOLUMBEANU ${ }^{\mathrm{a}}$ and L. GÁL ${ }^{\mathrm{b}}$ \\ a "POLITEHNICA" University of Bucharest, Center for Technological \\ Electronics and Interconnection Techniques (CETTI), Splaiul \\ Independentei 313, 77206-Bucharest, Romania ${ }^{\mathrm{b}}$ Technical University \\ of Budapest, Department of Electronics Technology, Goldman $t$. \\ 3, Budapest, H-1111, Hungary
}

(Received 29 June 1999; In final form 20 July 1999)

The actual generations of integrated circuits are characterized, inter alia, by very high frequencies or very high speeds. The dramatic evolution of the semiconductor's technology establishes a greater "pressure" to the design and the manufacturing of the passive interconnection structure from PCB/MCM electronic modules. In these conditions the reference planes (power and ground planes) have a more and more important contribution. The paper intents to present the effect of different configuration reference planes on the characteristics of the high speed/high frequency interconnection lines. The first part deals with modeling and simulation of usual practical interconnection geometries. A computer modeling of meshed structures was realized and Spice models for a good compatibility with circuit simulators were obtained. $S-, Y-, Z$ - parameters and radiation patterns were calculated, too. The second part contains measurements made by a vector network analyzer as regards to different practical configurations manufactured at Technical University of Budapest.

Keywords: PCB/MCM; reference plane; modeling; simulation; CAD design

*Corresponding author. Tel.: +401411-66-74, Fax: +401411-66-74, e-mail: cetti@ cadtieccp.pub.ro 


\section{INTRODUCTION}

Ideally, power and ground distribution should consist of planes to define a very good controlled impedance environment. In practical PCB/ MCM design and manufacturing situations, unfortunately, this requirement is only sometimes achieved due to the high level of component (die)/routing densities and the necessity to introduce vias between signal layers separated by a reference plane. Since the concept of infinite reference planes have to be kept as far as possible, the designers have defined hatched (meshed) power and ground planes which are proper for some applications but not so adequate for others. The objective of this paper is to simulate, analyze, and measure the influence of these planes to determine the field of applications in which this kind of passive structures could be used without losses in circuit performances.

An usual asked question is "why is it necessary to define hatched reference structures?". The answer could start long and interesting discussions in the field of technological electronics. With this solution the designer can introduce a greater number of signal vias between the layers, can increase the number of active layers for a signal connections and, in these conditions, can increase the wiring capacity; the manufacturer can fabricate also cost effective PCB/MCM modules [3]. Unfortunately, there will appear disadvantages, too. One of the most important, from the signal integrity point of view, due to the non-ideal reference planes, is the variation of characteristic impedance of the line values around the value for the full metallization reference planes.

Usually, two mesh orientation are taken into account: $45^{\circ}$ and $90^{\circ}$ (orthogonal). In the first case the angle between a signal track and a line of the reference structure is $45^{\circ}$. This solution is not adequate due to the relative high deviation of characteristic impedance in comparison with the ideal value obtained from theory (or even from measurements with an infinite full metallization reference plane) and to the design difficulties [2]. The choice of orthogonal hatched power/ground plane structures offers better conditions because all the signal lines are routed above a longitudinal part of these planes. To simplify the analyze we shall consider that the power will be routed as normal signal interconnection trees (but, of course, with a larger width) and, for this reason will not be taken into consideration in this contribution, and only the ground plane will be studied as a hatched passive interconnection structure (Fig. 1). 


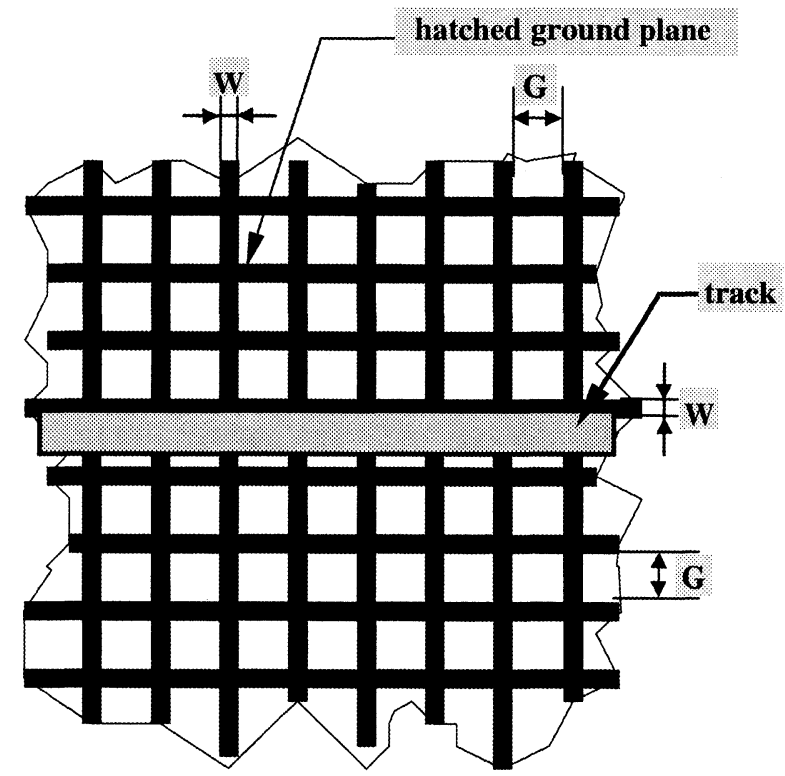

FIGURE 1 Track above a hatched ground plane.

An important problem regarding to the values of the characteristic impedance is the overlapping between the track and the ground plane. The greater distance between the center lines of route and ground plane, the larger values of characteristic impedance (due to the increasing of line inductance and the decreasing of line capacitance) will be obtained.

The differences given to the ideal situation appear also since the current return path are not the smallest geometrical path, but the smallest impedance path. For this reason the currents especially flow right beneath their respective signal routes, but in opposite directions. Due to the hatched (meshed) planes the return path can be greater than the smallest impedance path [5].

\section{MODELING AND SIMULATION}

In the first part a computer simulation was used to find the adequate geometry for studies and measurements. Multiple interconnection 
geometries were analyzed with Quickfield, program destined for 2D finite elements simulations [7], but only microstrip lines, buried microstrips (for instance soldermask coated microstrip lines at PCB modules) and striplines good or very good for high speed/high frequency applications are fitted. The computer used for modeling and simulation was an IBM PC/AT PentiumII/233 MHz with $64 \mathrm{MB}$ EDO-RAM memory. In Figure 2 two cases of the same controlled impedance geometry are presented: singular signal track over a ground plane (a-full metallized plane, b-hatched plane), microstrip geometry $[1,4]$.

One can be observed that with a non-compact ground structure the distribution of electric/magnetic fields is a bit different, the line parameters are not constant versus the length of the track, and the environment has a characteristic impedance not so good controlled, leading to a performance decreasing of the electronic module. In Figure 3, where is presented the $3 \mathrm{D}$ view of a simulated structure [6], it is shown that the return average current path is placed almost beneath the signal track and, if the hatched configuration is adequate constructed, the return path is only a bit greater than the smallest impedance path, so it is
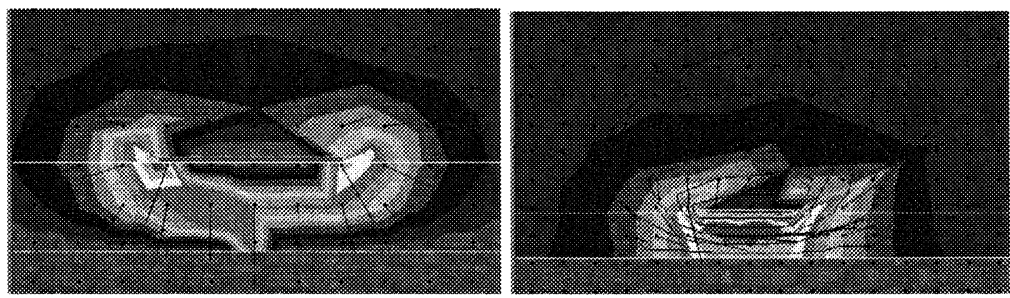

a)
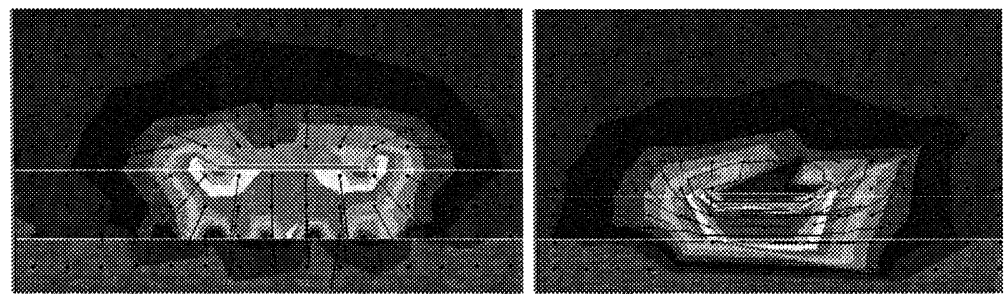

b)

FIGURE 2 Simulation of interconnection geometries with compact/hatched ground plane. 


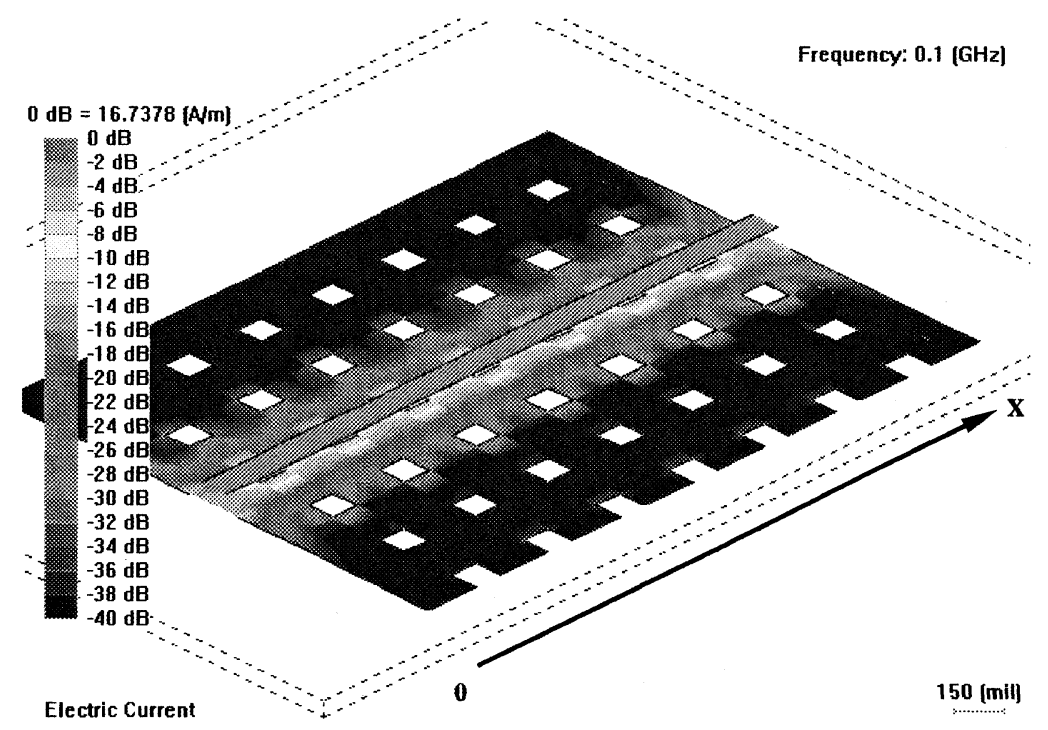

FIGURE 3 3-D and average current density view of a simulated structure.

TABLE I Spice parameters of the lumped model

\begin{tabular}{lccc}
\hline Frequency $[\mathrm{MHz}]$ & $L_{s}[\mathrm{nH}]$ & $C_{p}[p F]$ & $R_{s}[\Omega] \cdot 10^{-2}$ \\
\hline 10 & 19.45 & 6.675 & 4.282 \\
20 & 19.42 & 6.764 & 4.303 \\
50 & 19.27 & 6.789 & 4.369 \\
66 & 19.14 & 6.811 & 4.383 \\
100 & 18.77 & 6.881 & 4.234 \\
200 & 16.84 & 7.273 & 3.455 \\
\hline
\end{tabular}

a good situation [5]. The electromagnetic simulation has lasted about 9800 seconds and had cells/unknowns 1364/2251 for each frequency. Because this kind of configuration may be used in high speed PCB/ MCM modules it is necessary to extract the lumped equivalent circuit model to export to a Spice circuit simulator elements for time domain simulations. The RLCG lumped model was calculated at 10,20, $50,66,100$ and $200 \mathrm{MHz}$ and obtained parameters in Table I are presented. A Spice simulation with above parameters was realized and, after measurements of the 4th test structure, a good match between results was achieved. 
At the end of the electromagnetic simulation the $Z$ - and $S$ parameters of the structure were obtained, too. They are listed below and are offered for the same frequencies from above.

\begin{tabular}{lcccccc}
\hline$f[G H z]$ & $\operatorname{Re}[Z(1,1)]$ & $\operatorname{Im}[Z(1,1)]$ & $\operatorname{Re}[Z(1,2)]$ & $\operatorname{Im}[Z(1,2)]$ & $\operatorname{Re}[Z(2,2)]$ & $\operatorname{Im}[Z(2,2)]$ \\
\hline $1 . e-2$ & 41.96 & -2352 & 41.91 & -2350 & 41.9 & -2348 \\
$2 . \mathrm{e}-2$ & 20.99 & -1176 & 20.95 & -1176 & 20.96 & -1174 \\
$5 . \mathrm{e}-2$ & 8.403 & -468.7 & 8.375 & -471.4 & 8.392 & -468 \\
$6.6 \mathrm{e} .2$ & 6.37 & -354. & 6.342 & -357.7 & 6.362 & -353.4 \\
0.1 & 4.211 & -231.3 & 4.181 & -237.2 & 4.206 & -230.9 \\
0.2 & 2.125 & -109.4 & 2.079 & -121.7 & 2.124 & -109.2 \\
\hline
\end{tabular}

\begin{tabular}{llccccc}
\hline$f[G H z]$ & $\operatorname{Re}[S(1,1)]$ & $\operatorname{Im}[S(1,1)]$ & $\operatorname{Re}[S(1,2)]$ & $\operatorname{Im}[S(1,2)]$ & $\operatorname{Re}[S(2,2)]$ & $\operatorname{Im}[S(2,2)]$ \\
\hline $1 . \mathrm{e}-2$ & $1.096 \mathrm{e}-3$ & $1.552 \mathrm{e}-3$ & 0.9991 & $-2.283 \mathrm{e}-2$ & $-5.474 \mathrm{e}-004$ & $1.591 \mathrm{e}-3$ \\
$2 . \mathrm{e}-2$ & $1.016 \mathrm{e}-3$ & $3.111 \mathrm{e}-3$ & 0.9981 & $-4.561 \mathrm{e}-2$ & $-6.223 \mathrm{e}-004$ & $3.19 \mathrm{e}-3$ \\
$5 . \mathrm{e}-2$ & $1.216 \mathrm{e}-3$ & $7.766 \mathrm{e}-3$ & 0.9921 & -0.1137 & $-4.037 \mathrm{e}-004$ & $7.958 \mathrm{e}-3$ \\
$6.6 \mathrm{e} .2$ & $1.59 \mathrm{e}-3$ & $1.022 \mathrm{e}-2$ & 0.9869 & -0.1498 & $-1.371 \mathrm{e}-005$ & $1.047 \mathrm{e}-2$ \\
0.1 & $2.98 \mathrm{e}-3$ & $1.526 \mathrm{e}-2$ & 0.9716 & -0.2257 & $1.424 \mathrm{e}-003$ & $1.563 \mathrm{e}-2$ \\
0.2 & $1.124 \mathrm{e}-2$ & $2.778 \mathrm{e}-2$ & 0.8931 & -0.4385 & $9.921 \mathrm{e}-003$ & $2.844 \mathrm{e}-2$ \\
\hline
\end{tabular}

TABLE II Characteristic impedance $v s$. frequency

\begin{tabular}{lcc}
\hline Frequency $[M H z]$ & $\operatorname{Re}\left(Z_{0}\right)[\Omega]$ & $\operatorname{Im}\left(Z_{0}\right)[\Omega]$ \\
\hline 10 & 53.637 & -0.46 \\
20 & 53.632 & 0.004 \\
50 & 53.62 & 0.278 \\
66 & 53.618 & 0.321 \\
100 & 53.608 & 0.362 \\
200 & 53.572 & 0.388 \\
\hline
\end{tabular}

The characteristic impedance of the transmission line structure (signal track and meshed ground plane) presents the dependence of frequency from Table II.

The simulation destined for radiation pattern generation offered an overview regarding the electromagnetic radiation of such a special structure (only E-field is possible to be presented). In Figures 4, 5 and $62-D$ polar pattern, 3-D pattern (general view) and a top view of the radiation diagram are presented. 


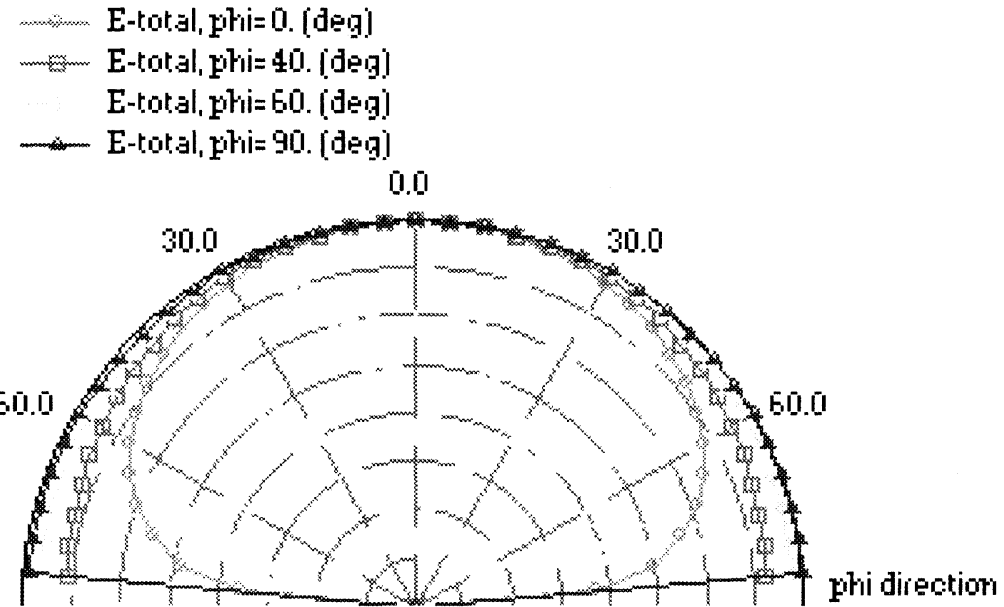

FIGURE 4 2-D polar pattern of structure.

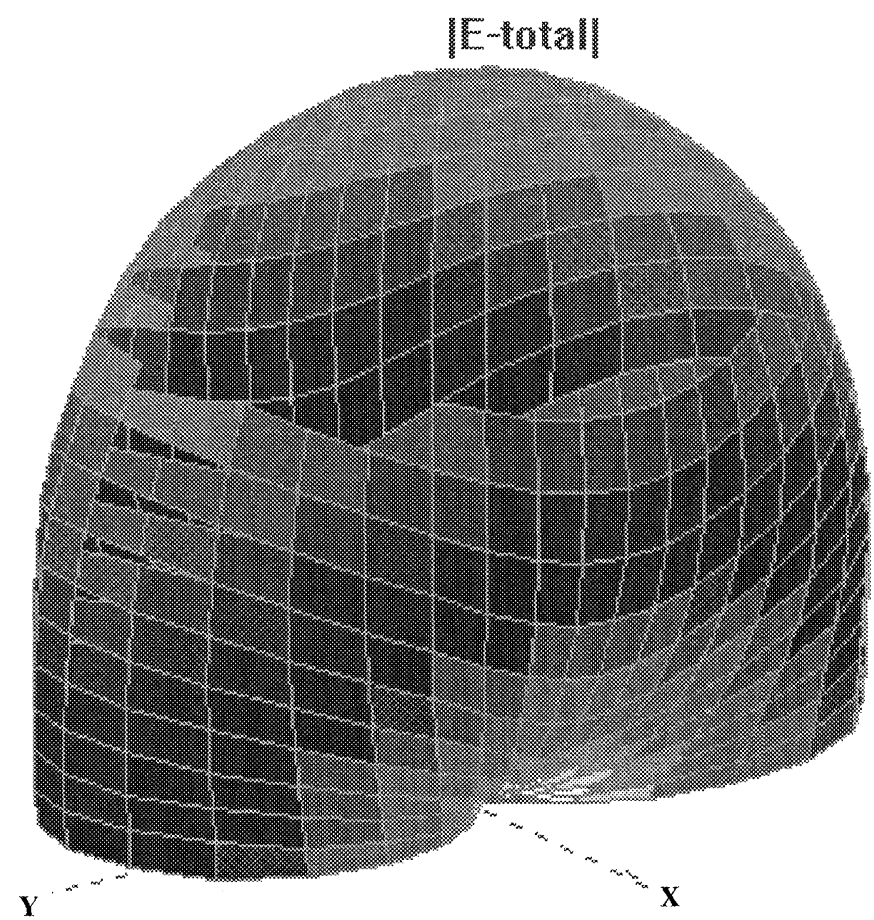

FIGURE 5 3-D pattern (general view). 


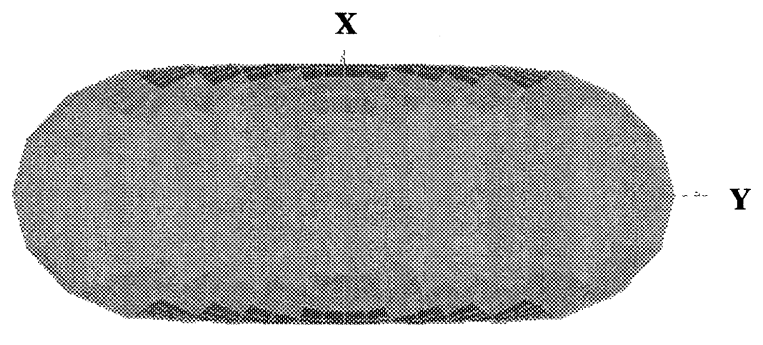

FIGURE 6 3-D pattern (top view).
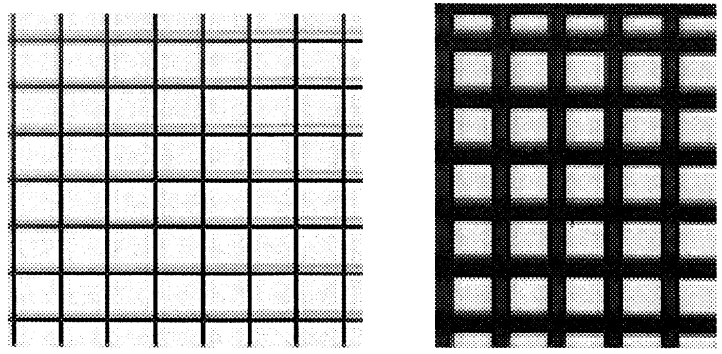

1 st

2nd

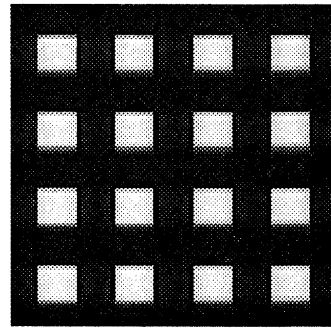

3rd

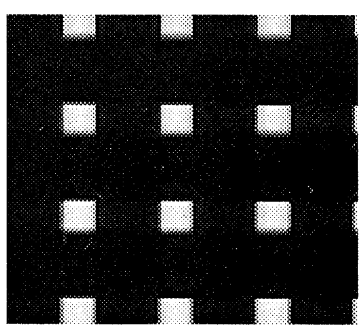

4th

FIGURE 7 Ground planes of PCB test structures. 


\section{MEASUREMENTS}

Due to the interest of hatched ground plane usage in practice, we have prepared four PCB test structures (it could be considered there are also MCM-L structures), as it is shown in Figure 7. The gap parameter (G) was kept constant and the width parameter $(W)$ was chosen to be variable (Tab. III).

The dimensions of structures were identical, 104.65 by $76.2 \mathrm{~mm}$ ( 4120 by 3000 mils), the distance between measuring pads being $101.6 \mathrm{~mm}$ (4000 mils). The PCB parameters are FR4 type, $h=1.5 \mathrm{~mm}$,

TABLE III Parameters of analyzed ground planes

\begin{tabular}{lcccc}
\hline & 1st structure & 2nd structure & 3rd structure & 4th structure \\
\hline G & 100 & 100 & 100 & 100 \\
$W$ & 10 & 50 & 100 & 200 \\
MAR (\%) & 9.09 & 33.33 & 50 & 66.67 \\
No. of OX gaps & 37 & 27 & 20 & 13 \\
No. of OY gaps & 27 & 20 & 14 & 9 \\
Total no. of gaps & 999 & 540 & 280 & 117 \\
\hline
\end{tabular}

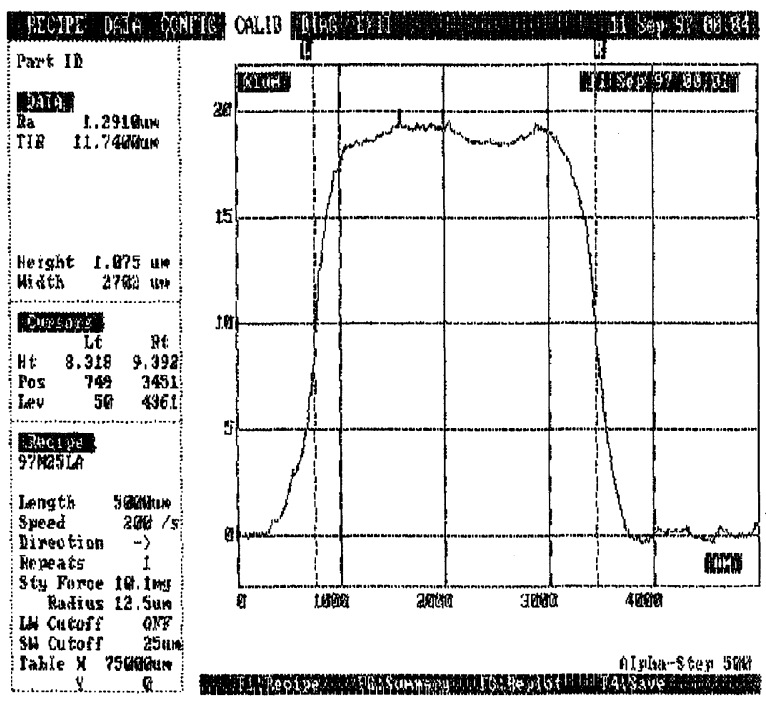

FIGURE 8 Measurement of track width. 

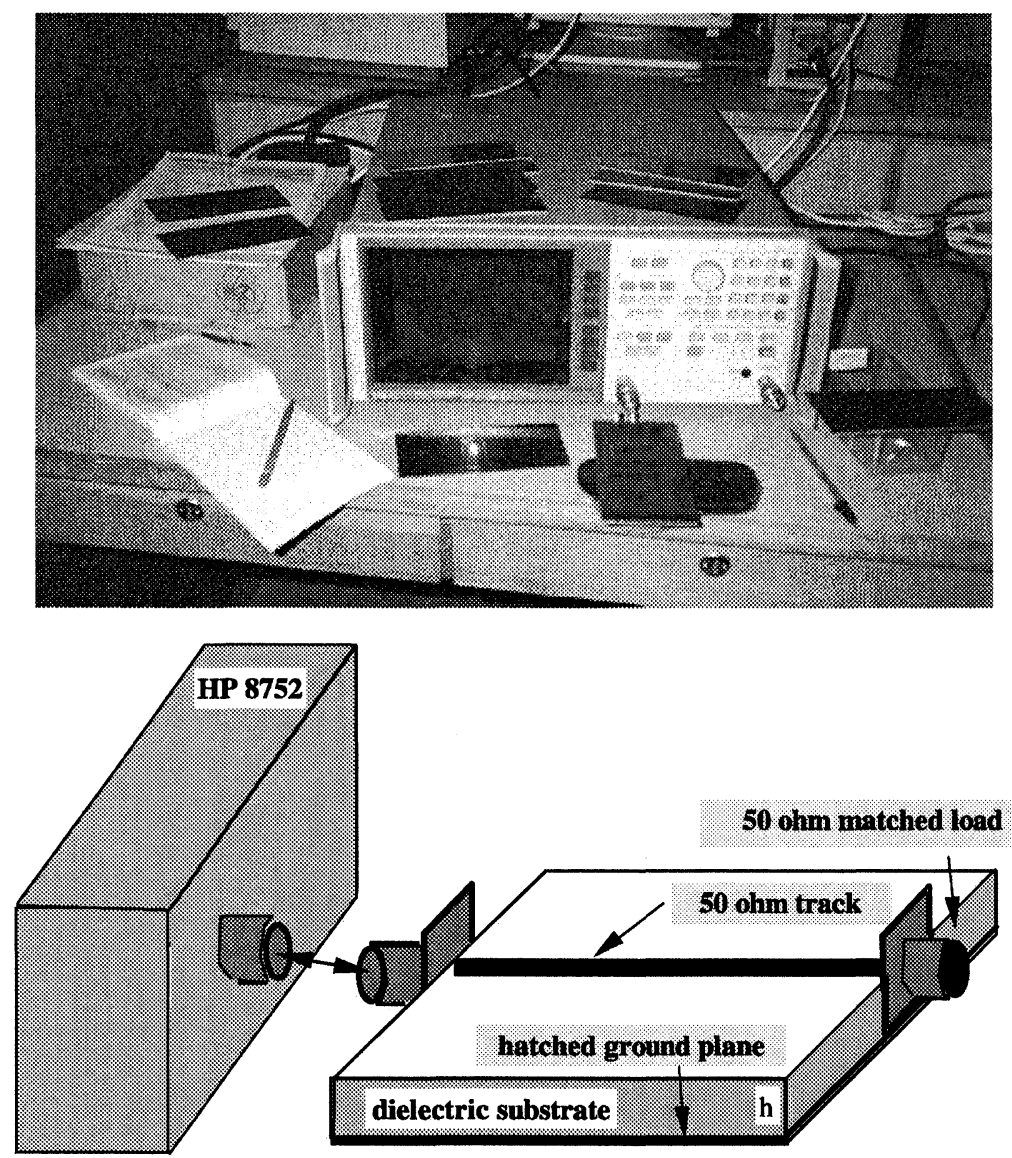

FIGURE 9 Image of the test equipment and measure configuration.

TABLE IV Practical characteristic impedance ranges and min./max. deviations

\begin{tabular}{lccc}
\hline & $\begin{array}{c}Z_{0} \text { range }[\Omega] \\
\operatorname{Re} Z_{0} / \operatorname{Im} Z_{0}\end{array}$ & $\begin{array}{c}\text { Deviation for } \operatorname{Re} Z_{0} \\
\text { min. value [\%] }\end{array}$ & $\begin{array}{c}\text { Deviation for } \operatorname{Re} Z_{0} \\
\text { max. value [\%] }\end{array}$ \\
\hline 1st structure & $\frac{42.623 \ldots 53.525}{-2.469 \ldots 6.260}$ & -14.75 & 7.05 \\
2nd structure & $\frac{46.174 \ldots 55.441}{-2.978 \ldots 7.416}$ & -7.65 & 10.88 \\
3rd structure & $\frac{46.736 \ldots . .55 .770}{-5.327 \ldots 6.789}$ & -6.53 & 10.54 \\
4th structure & $\frac{46.908 \ldots .52 .250}{-3.971 \ldots 3.260}$ & -6.18 & 4.50 \\
\hline
\end{tabular}


$t=17.5 \mu \mathrm{m}$, and $\varepsilon_{r}=4.66$. The $50 \Omega$ signal test line has a theoretical width of $2698 \mu \mathrm{m}$. Because of PCB-CAD resolution $(1 \mathrm{mil}=25.4 \mu \mathrm{m})$ the designed track width was only of $106 \mathrm{mil}=2692.4 \mu \mathrm{m}$, but fortunately, after the manufacturing (Fig. 8), a real width of $2702 \mu \mathrm{m}$, very closed to the theoretical value, was obtained. The measurement were realized with Alpha-Step 500 equipment, made by Tencor company.

The mesh aperture ratio (MAR) is given by the formula:

$$
\operatorname{MAR}=\frac{W}{W+G}
$$

The measurement equipment for electrical parameters was a HewlettPackard 8752 vector network analyzer, with a bandwidth between $300 \mathrm{kHz}$ and $3 \mathrm{GHz}$ (Fig. 9).

In Table IV the values obtained after the measurements are presented. The origin of time was chosen at the output point of analyzer, the first edge of the board being at the location of about $250 \mathrm{ps}$ $(4.4 \mathrm{~cm})$. The table lists practical characteristic impedance ranges of tested PCB structures and minimum/maximum deviations obtained to the theoretical impedance.

Depending on the PCB/MCM module design objectives there are different reference plane design strategies. For example, due to its geometrical and electrical characteristics, the first test structure is not suitable for high performance systems. Second and third structures are suitable in the middle range of applications, especially used when a large number of vias is necessary to be introduced. But only the fourth reference plane configuration offers a good quality operating environment for signal propagation.

\section{CONCLUSIONS}

The performance of PCB/MCM modules having hatched (meshed) power and ground planes to generate controlled impedance environment depends strongly on the mesh parameters ( $W$ and $\mathrm{G}$ ) and the number of vias connected to this structure to avoid resonance effects which could appear in such a non-compact structures.

The conclusion is that the utilization of hatched reference planes, which are also controlled impedance geometries, represents a good 
solution only if the designer can evaluate the variation range of the line parameters and if this range is suitable for the current application. In this paper was shown that the 4th test structure is the best solution to define a good controlled impedance environment, the disadvantage in this case being the reduced number of gaps in the plane, so a reduced number of signal vias.

A new approach in this field is the Interconnected Mesh Power System Topology (IMPS) used for fabrication of low cost MCM modules [8], topology in which the layers destined only for reference purposes are eliminated, and an mixture of signals, power and ground routes is created. In this way a $4 \mathrm{~L}-\mathrm{MCM}$ is transformed in a $2 \mathrm{~L}-\mathrm{MCM}$, unfortunately also the wiring density being reduced by half.

A future task will be to keep constant $W$ and to vary the gap $\mathrm{G}$ for a better fitting between vias diameters, gap sizes, and circuit performances.

\section{Acknowledgments}

The authors would like to take this opportunity to thank Technical University of Budapest (Electronics Technology and Microwave Departments), Prof. Zsolt Illyefalvi-Vitéz, especially, Dr. János Pinkola, Dr. Miklós Ruszinkó and Dr. Pál Németh for their continuous support for the experimental work and their valuable suggestions. We thank also Dr. Jian Zheng, Ph.D. who offered us the IE3D electromagnetic simulation software system and good advises for our CAD operations.

It is a pleasure to acknowledge the big contribution of The Ministry of Culture and Education from Hungary for our working at Technical University of Budapest.

At last, but not at least, we thank Dipl. Eng. Attila Telegdy for his support and for the interesting discussions regarding the amazing world of high frequencies circuits.

\section{References}

[1] Codreanu, N. D., Svasta, P., Cristea, I. and Ionescu, C., "Aspects Concerning Modeling/Simulation of Some Discontinuities from Passive Interconnection Structures", The 20-th International Seminar on Semiconductor and Hybrid Technologies, Sofia, Bulgaria, September 26-28, 1998, pp. 19-26.

[2] Müller, J., Thust, H. and Drüe, K. H., "RF-Design Considerations for Passive Elements in LTTC", ISHM 1994 Proceedings, pp. 357-362, November 1994. 
[3] Svasta, P., Codreanu, N. D., Ionescu, C., Golumbeanu, V. and Cristea, I., "Simulation of Multichip Module Structures", EC-MCM'99, The 5-th European Conference on MultiChip Modules, Londra, Marea Britanie, February 1-2, 1999 pp. $48-54$

[4] Codreanu, N. D., "Modeling and Simulation of Some Controlled/Uncontrolled Impedance Interconnection Geometries", ICDA Symposium, December 10, 1997, Proceedings in press.

[5] Scott, K. J. (1994). "Practical Simulation on Printed Circuit Boards and Related Structures", pp. 109-112, John Wiley \& Sons Inc.

[6] Zeland Software. Inc., "IE3D User's Manual, Release 5.2", 1999.

[7] Tera Analysis Company, "Students' Quickfield (TM)", Version 3.4 User's Guide, 1995.

[8] Low, Y. L., Schaper, L. W. and Ang, S. S., "Modeling and Experimental Verification of the Interconnected Mesh Power System (IMPS) MCM Topology", IEEE Transactions on CPMT-Part B, 20(1), February 1997, pp. 42-49. 

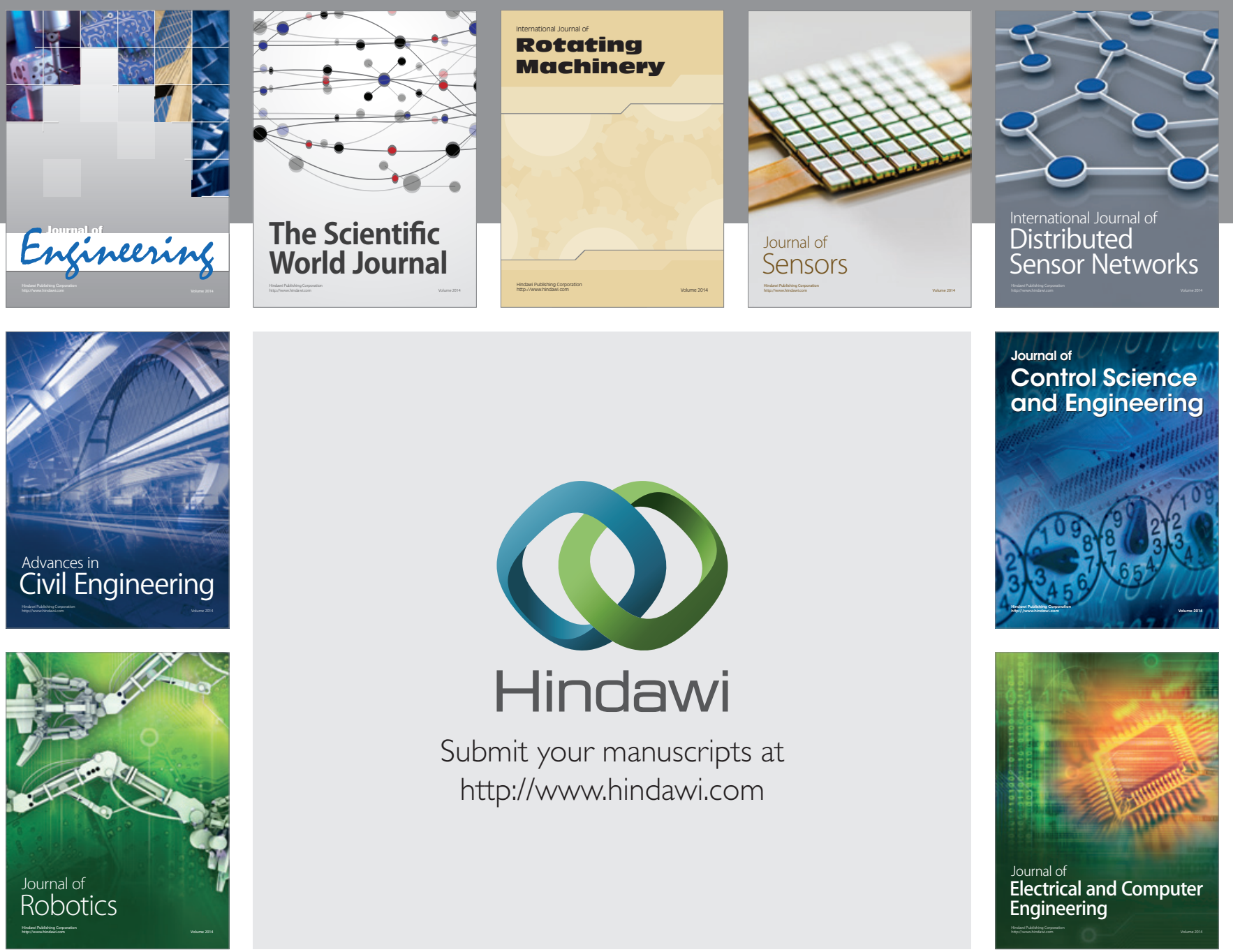

Submit your manuscripts at

http://www.hindawi.com
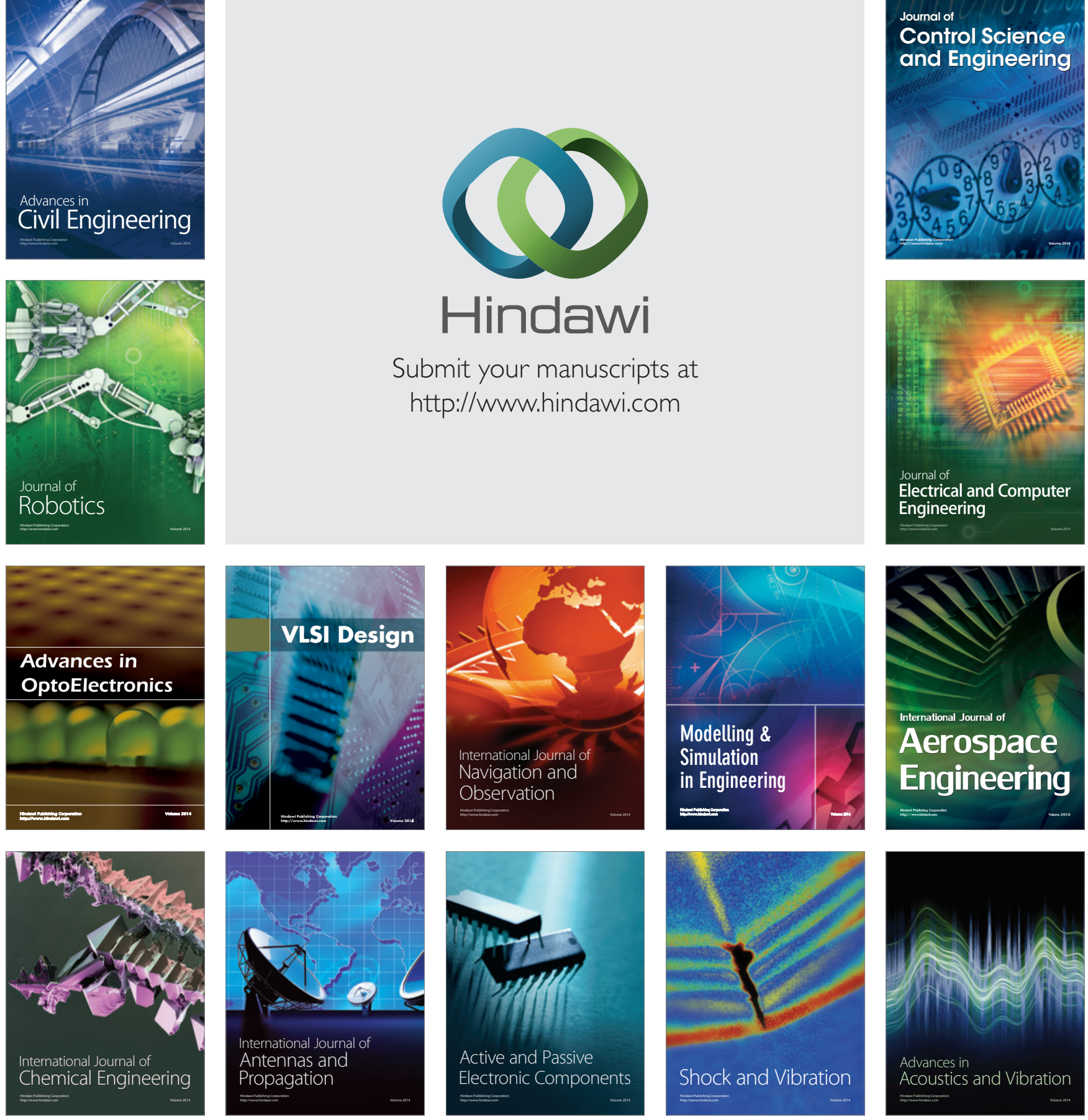